\title{
COMPARISON OF EFFICACY OF ORAL DROTAVERINE PLUS MEFENAMIC ACID WITH PARACERVICAL BLOCK AND WITH INTRAVENOUS SEDATION FOR PAIN RELIEF DURING HYSTEROSCOPY AND ENDOMETRIAL BIOPSY
}

\author{
J. B. SHARMA, J. ARUNA, PRAVEEN KUMAR, KALLOL KUMAR ROY, NEENA MALHOTRA, \\ SUNESH KUMAR
}

\section{ABSTRACT}

BACKGROUND: Office hysteroscopy with endometrial biopsy is usually the first investigation for abnormal uterine bleeding and other uterine diseases. AIMS: To evaluate the effect of oral drotaverine with mefenamic acid on pain perception during hysteroscopy and endometrial biopsy and to compare it with that of paracervical block using $1 \%$ lignocaine and with that of intravenous sedation using diazepam with pentazocine. SETTINGS AND DESIGN: O utpatient gynecological department and open randomized trial. MATERIALS AND METHODS: O ne hundred twenty women undergoing hysteroscopy and endometrial biopsy were randomized into 3 groups. Group I received tablet containing drotaverine hydrochloride $(80 \mathrm{mg})+$ mefenamic acid $(250 \mathrm{mg})$, group II received lignocaine paracervically and group III received intravenous diazepam. The intensity of pain during the procedure, 30 and 60 minutes later on visual analog scale (VAS) was assessed. STATISTICAL ANALYSIS: Statistical analysis was performed using Kruskal-Wallis test, with the Bonferroni correction, the t test, and the $\chi^{2}$ test. RESULTS: Groups were similar in age, parity, vaginal birth or relevant medical history. A statistically significant difference in pain scores was noted among the 3 groups

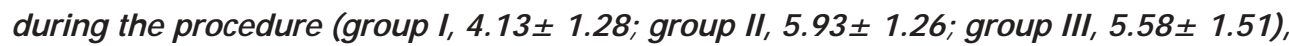
$(P<0.001)$; as well as 30 minutes later (group I, 1.78 0.89 ; group II, 2.53 \pm 0.81 ; group

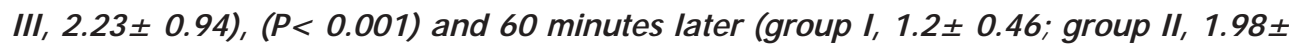
0.83; group III, 1.68 \pm 0.75$)$, (P<0.001). VAS at different time intervals among the groups was also statistically significant. No adverse effects were observed. CONCLUSIONS: Oral drotaverine with mefenamic acid is effective in women undergoing hysteroscopy and endometrial biopsy.

Key words: Hysteroscopy or endometrial biopsy, pain, preoperative care or premedication

DOI: $10.4103 / 0019-5359.53394$

Department of Obstetrics and Gynecology, All India Institute of Medical Sciences, New Delhi, India

\section{Correspondence:}

Dr. J. B. Sharma

Al/61 Azad Apartments, Sri Aurobindo Marg, Hauz Khas, New Delhi - 110 016, India

E-mail: jbsharma2000@gmail.com

\section{INTRODUCTION}

Hysteroscopic examination with endometrial biopsy is currently the most informative investigation for patients with abnormal uterine bleeding and infertility. Previously, this 
procedure was done under general or regional anesthesia. Hysteroscopy with endometrial biopsy under local anesthesia has gained wider acceptance to avoid the risk of general anesthesia. ${ }^{[1]}$ Schoenfeld et al. and Kajve et al. concluded that intravenous diazepam and pentazocine is effective for pain relief during minor gynecological operations and tubal ligation. ${ }^{[2,3]} \mathrm{A}$ mixture of pentazocine and diazepam was used by them for minor gynecological procedures. Satisfactory operating conditions were achieved in $98 \%$ of the patients without any adverse reactions. With the advent of locally acting better drugs, many centers stopped using intravenous sedation. Various methods of local anesthesia have been studied to reduce the pain, and it was suggested that paracervical block, topical lignocaine, intracervical lignocaine may reduce the pain, but the evidence is not strong. ${ }^{[4-6]}$ It could be due to inability of the paracervical block to affect the sensitivity of the uterine fundus. Similarly techniques involving dilatation of cervix, like introduction of hysteroscope, result in increased pain due to prostaglandin release. Therefore, it seems logical to prime the cervix and use prostaglandin synthesis inhibitors prophylactically before the procedure. Drotaverine hydrochloride, an isoquinoline derivative, is a potent spasmolytic which acts directly on the smooth muscles by inhibiting phosphodiesterase activity and is devoid of any anticholinergic side effects. ${ }^{[7]}$ Because of this antispasmodic action, it is widely used in biliary and renal colic, for augmentation of labor, dysmenorrhea and before instrumental diagnostic procedures. ${ }^{[7-10]}$ Mefenamic acid, a nonsteroidal anti-inflammatory drug, inhibits cyclooxygenase enzyme and exerts its anti-inflammatory and analgesic action by inhibiting prostaglandin synthesis. It is widely used in gynecology to treat dysmenorrhea and menorrhagia. By virtue of two different mechanisms of action due to different active ingredients, a fixeddose combination of drotaverine hydrochloride with mefenamic acid would be expected to reduce the discomfort of the procedure. Both are well absorbed orally. Peak plasma concentration of drotaverine is attained within 1 hour; and that of mefenamic acid, in 2 to 4 hours. The two molecules in a fixed-dose combination provide comprehensive pain relief. Drotaverine allays the early-onset pain and potentiates the sustained analgesic effect of mefenamic acid. As the special property of fixed dose combination having synergistic effects allows achieving relief in early-onset pain by drotaverine and sustained analgesic effect by mefenamic acid, we hypothesized that oral tablet containing drotaverine and mefenamic acid will be effective in relieving pain during hysteroscopy and endometrial biopsy, cost effective and less invasive. We therefore studied the effect of fixed-dose (oral) combination of drotaverine $(80 \mathrm{mg})$ with mefenamic acid $(250 \mathrm{mg}$ ) on pain perception during hysteroscopy and endometrial biopsy and compared it with that of paracervical block and with that of intravenous sedation, both of which are more invasive.

\section{MATERIALS AND METHODS}

This randomized trial was conducted between January 2007 and July 2007 in the outpatient gynecology department of All India Institute of Medical Sciences, New Delhi. The study was approved by the ethics committee of the institute. The sample size was calculated with 
the help of a statistician, taking alpha and beta errors into consideration and keeping the power of the study above $80 \%$; so a total of 120 women with a medical indication for hysteroscopy and endometrial biopsy (infertility, abnormal uterine bleeding) were recruited. The criteria for inclusion in the study were (1) all women should be requiring hysteroscopy or endometrial biopsy for infertility or abnormal uterine bleeding and (2) all of them should have given informed written consent. The patients were informed about details of the study in their language before taking their written consent. The criteria for exclusion from the study were (1) being pregnant; (2) having a known sensitivity to nonsteroidal anti-inflammatory drugs, lignocaine; (3) having peptic ulcer disease, inflammatory bowel disease, porphyrias, genital infections, cervical stenosis, serious cardiac disease; (3) being unable or unwilling to provide informed consent; and (4) having history of cervical surgery. This study was an open-label randomized trial where all the 120 patients were randomized using a predetermined computergenerated randomization code into 3 groups [Figure 1]. In each group, there were 40 patients. Group I patients received fixed-dose oral tablet containing drotaverine $(80 \mathrm{mg})$ with mefenamic acid $(250 \mathrm{mg})$. Group II patients received paracervical block with $10 \mathrm{~mL}$ of $1 \%$ lignocaine solution. Group III patients received intravenous sedation with diazepam $(0.2 \mathrm{mg} /$ $\mathrm{kg}$ body weight) and pentazocine $(0.6 \mathrm{mg} /$ $\mathrm{kg}$ body weight). In this open-label study, the procedure was performed by the same resident gynecologist throughout the study period who knew the group to which the patient belonged and accordingly administered the drug. The outcome measure (pain score) was evaluated by a resident doctor throughout the study who did not know the treatment protocol. Group I patients were instructed to take tablet Drotin-M [Martin and Harris Private Limited, India] 1 hour before the procedure, and no other analgesia or anesthesia was used on them. Women in all the groups were placed in lithotomy position and bimanual examination was done. After cleaning and draping, a bivalved speculum was inserted to expose the cervix; the anterior lip of cervix was grasped with volsellum forceps. As most diagnostic hysteroscopies in our department are performed by resident doctors, volsellum and speculum are routinely used by them for hysteroscopies and they are not yet trained to perform hysteroscopies by vaginoscopic approach; hence hysteroscopies were done in the traditional way using speculum and holding anterior lip of cervix with volsellum forceps. In group II, paracervical block was preformed using 22-gauge hypodermic needle, and 10 $\mathrm{mL}$ of $1 \%$ lignocaine [Xylocard, Astra Zeneca Pharma Limited, India] was injected at 3- and 9-o'clock position at the junction of the cervix and vagina in divided doses. Group III patients were given intravenous diazepam $(0.2 \mathrm{mg} /$ kg body weight) [Lori, Neon Laboratories Limited, Thane, India] + pentazocine $(0.6 \mathrm{mg} /$ kg body weight) [Fortwin, Ranbaxy Laboratories Limited, Ahmedabad, India]. Hysteroscopy and endometrial biopsy were started after 1 hour, 5 minutes and 10 minutes, respectively, in group I, group II and group III following the drug administration. If cervical dilatation was required, it was performed and noted. A rigid 5-mm diameter hysteroscope with a $30^{\circ}$ fore-oblique view (Karl-Storz, Germany) was inserted into the uterine cavity under direct vision. Uterine distension was maintained by a 


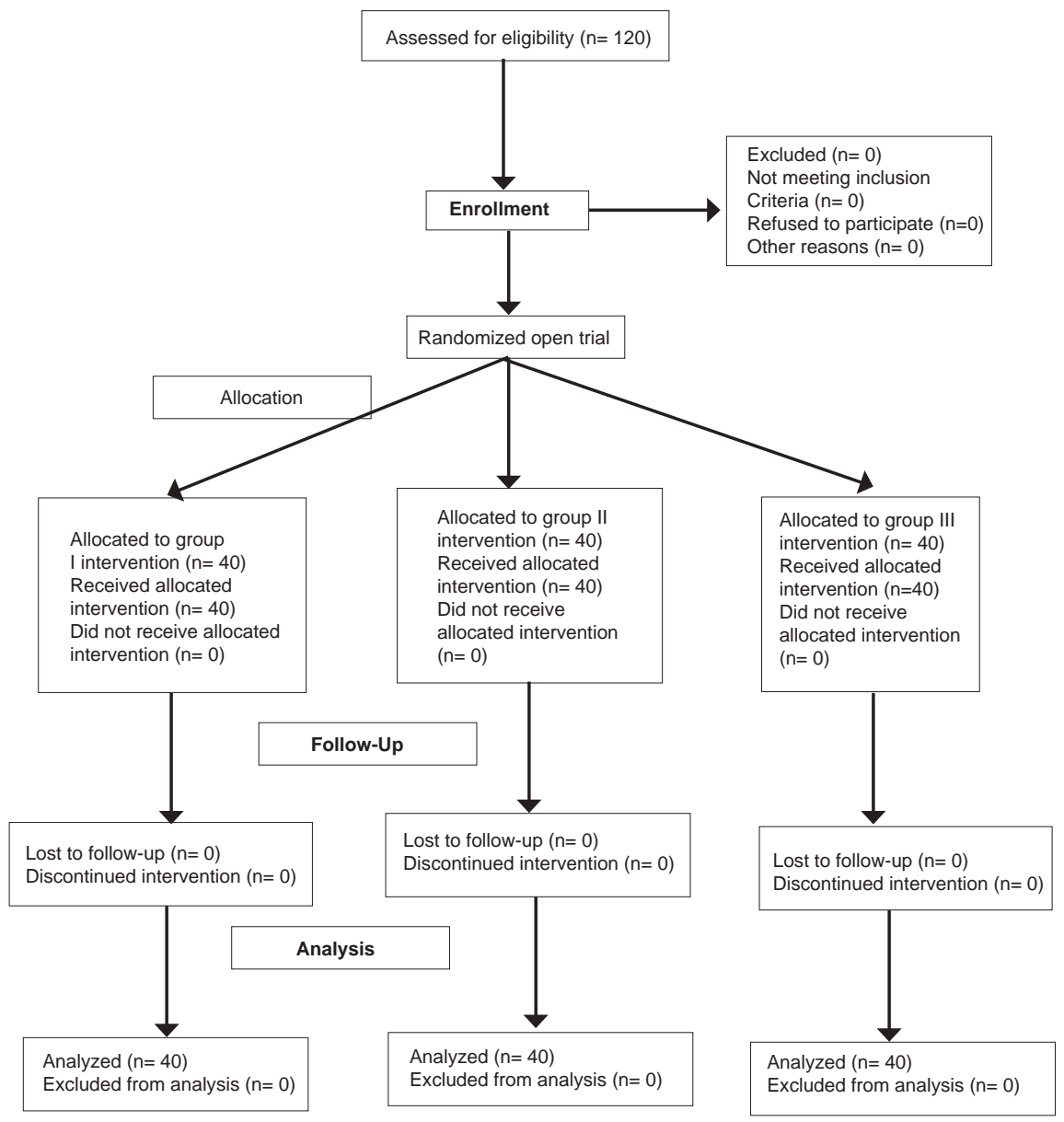

Figure 1: Flow chart of recruitment of patients

steady stream of normal saline solution using a pressure bag applied to the plastic bottle containing normal saline, which was hung at a height of about 6 feet. The pressure bag was inflated up to $300 \mathrm{~mm} \mathrm{Hg}$. The image was displayed on the television monitor so that the operator and the patient could see the inside of the uterine cavity. Endometrial biopsy was performed using 4-mm Karman's plastic cannula (Chimco Bio-Medical Eng. Co., Sigma International, India). Vacuum was created by the $20-\mathrm{mL}$ plastic syringe attached to the other end of the cannula. The resident doctor evaluating the outcome measure asked the patients to score the worst pain experienced during the procedure and the degree of their discomfort after 30 minutes and 60 minutes of the procedure using a $10-\mathrm{cm}$ line visual analog scale (VAS: $0 \mathrm{~cm}$ - no pain, $10 \mathrm{~cm}$ - excruciating pain). No further followup was scheduled. No woman was excluded and the procedure was not abandoned at any point of time after recruiting. The data was analyzed using the statistical package for social 
Table 1: Demographic characteristics of the women in the study

\begin{tabular}{|c|c|c|c|c|c|}
\hline & Group I* $n=40$ & Group $I^{* *}, n=40$ & Group III ***, $n=40$ & $P$ value & Significance \\
\hline Age & $36.25 \pm 6.53$ & $37.35 \pm 6.12$ & $36.82 \pm 6.41$ & 0.74 & Not significant \\
\hline Parity & $1.48 \pm 1.58$ & $1.43 \pm 1.51$ & $1.38 \pm 1.49$ & 0.95 & Not significant \\
\hline Vaginal delivery & $1.40 \pm 1.61$ & $1.38 \pm 1.53$ & $1.43 \pm 1.52$ & 0.89 & Not significant \\
\hline Infertility & $47.5 \%(n=19)$ & $50 \%(n=20)$ & $47.5 \%(n=19)$ & 0.76 & Not significant \\
\hline Abnormal uterine bleeding & $52.5 \%(n=21)$ & $50 \%(n=20)$ & $52.5 \%(n=21)$ & 0.68 & Not significant \\
\hline Need of cervical dilatation & 2 & 3 & 3 & 0.95 & Not significant \\
\hline
\end{tabular}

*Group I- oral drotaverine and mefenamic acid, ** Group II- paracervical block with $1 \%$ lignocaine solution, ${ }^{* * *}$ Group III- intravenous sedation with diazepam and pentazocine

sciences (SPSS) 15. Statistical analysis was performed with Kruskal-Wallis test followed by Bonferroni correction. Change in VAS over the period of time was seen by applying repeated measure analysis followed by post hoc comparison. The $t$ test and the $\chi^{2}$ test were applied where appropriate. $P<0.05$ was considered statistically significant.

\section{RESULTS}

The characteristics of patients are given in Table 1. Of the 120 patients recruited, procedure was performed successfully in all, and at no point anyone was excluded from the study. All the data has been mentioned as mean \pm standard deviation, $95 \%$ confidence interval $(\mathrm{Cl})$ for mean with lower and upper bound values. There was no statistical difference in age, parity, vaginal deliveries and indication for hysteroscopy and endometrial biopsy among the three groups [Table 1]. The age ranged from 20 to 61 years with mean being 36.28 years, 37.75 and 36.82 years respectively. Parity ranged from 0 to 4 with mean being $1.48,1.40$ and 1.38 in the three groups, respectively. Infertility and abnormal uterine bleeding were the two most frequent symptoms of patients. The mean pain scores during the procedure, after 30 minutes and 60 minutes among the three groups are shown in Figure 1. Pain perception in group I patients
Table 2: Comparison of VAS at different intervals among the groups

\begin{tabular}{llcc}
\hline VAS $^{+}$ & Groups & $P$ value & Significance \\
\hline VAS 1 & I and II & 0.001 & Highly significant \\
& I and III & 0.001 & Highly significant \\
& II and III & 0.69 & Not significant \\
VAS 2 & I and II & 0.001 & Highly significant \\
& I and III & 0.08 & Not significant \\
& II and III & 0.41 & Not significant \\
VAS 3 & I and II & 0.001 & Highly significant \\
& I and III & 0.001 & Highly significant \\
& II and III & 0.16 & Not significant \\
\hline
\end{tabular}

+VAS- visual analog score, VAS 1- pain score during the procedure, VAS 2- pain score after 30 minutes, VAS 3- pain score after 60 minutes; $P<0.05$ considered statistically significant, Group I- oral drotaverine and mefenamic acid, Group II- paracervical block with $1 \%$ lignocaine solution, Group III- intravenous sedation with diazepam and pentazocine

during the procedure was $4.13 \pm 1.28(95 \%$ $\mathrm{Cl}, 3.71-4.54)$ and was significantly less $(P<$ $0.001)$ than that in the paracervical block group $5.93 \pm 1.26(95 \% \mathrm{Cl}, 5.52-6.33)$ and intravenous sedation group $5.58 \pm 1.51(95 \% \mathrm{Cl}, 5.14-6.01)$. Similarly, pain score reported after 30 minutes was $1.78 \pm 0.89(95 \% \mathrm{Cl}, 1.49-2.06)$ in group I; $2.53 \pm 0.81(95 \% \mathrm{Cl}, 2.26-2.79)$ in group II; and $2.23 \pm 0.94(95 \% \mathrm{Cl}, 1.91-2.54)$ in group III. Pain score after 60 minutes was $1.2 \pm 0.46$ (95\% Cl, 1.05-1.35) in group I; $1.98 \pm 0.83(95 \%$ $\mathrm{Cl}, 1.71-2.24)$ in group II; and $1.68 \pm 0.75$ (95\% $\mathrm{Cl}, 1.44-1.91)$ in group III. Pain was significantly less $(P<0.00)$ in group I after 30 and 60 minutes when compared with that in groups II and III [Figure 2]. The VAS score at different time intervals among the groups was also significant [Table 2]. One patient in drotaverine with mefenamic acid group complained of gastritis 


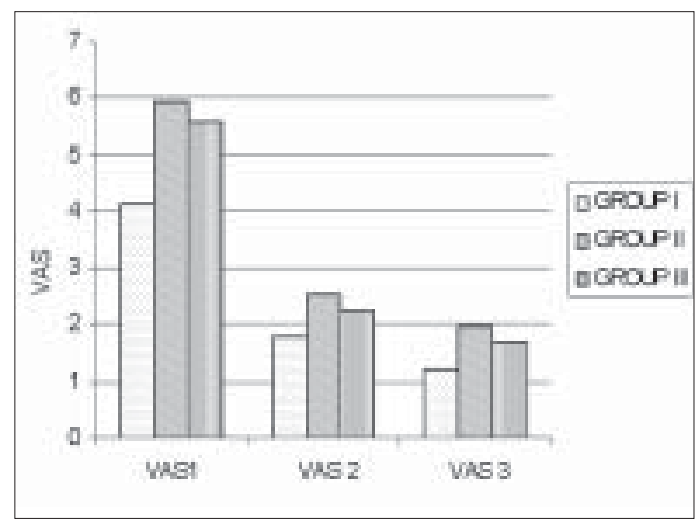

Figure 2: VAS scores in the three groups

VAS 1- during the procedure, VAS 2- after 30 minutes, VAS 3- after 60 minutes, Group I- oral drotaverine and mefenamic acid, Group II-paracervical block with 1\% lignocaine solution, Group III- intravenous sedation with diazepam and pentazocine

after 2 hours of ingestion, 4 complained of abdominal cramps after 1 hour of the procedure and no other adverse effects were noted; whereas 12 patients in group II complained of abdominal cramps after 1 hour of the procedure. In group III, 20 patients had dizziness, 4 had palpitations following the injection of drug and 12 continued to have dizziness after 1 hour of the procedure. Seven patients reported nausea and vomiting in group III following the procedure. In all the groups, none of the patients required medication or hospitalization, and symptoms subsided in the following few hours.

\section{DISCUSSION}

The data from this study demonstrates that the combination of drotaverine and mefenamic acid is effective in decreasing the pain during the procedure and its effect lasts longer than that of paracervical block or intravenous sedation. These two drugs have synergistic effects because their mechanisms of action are different. Despite the use of local anesthesia and intravenous sedation, the commonest reason for failure to complete the procedure is pain. Pain perceived in the cervix and uterine corpus appears to pass through 2 distinct neural pathways. A paracervical block aids in decreasing pain from cervical origin, but the extent of its effect on pain related to uterine activity is unclear. Paracervical lignocaine was found to be ineffective in reducing pain during endometrial biopsy and also carried the risk of inducing bradycardia, hypotension, convulsion, respiratory arrest and death..$^{[5]}$ In another randomized trial, Vercellini et al. demonstrated that paracervical block is ineffective in reducing the discomfort of hysteroscopy and noted that it is the endometrial biopsy which is the most painful part of the procedure. ${ }^{[6]}$ Broadbent et al. demonstrated that intracervical injection of lignocaine does not reduce the pain during hysteroscopy. ${ }^{[11]}$ Fritz et al., in 1997, in a randomized double-blind placebo-controlled trial concluded that $500 \mathrm{mg}$ of mefenamic acid 1 hour before hysteroscopy had no significant effect on the discomfort experienced during the procedure but did significantly reduce pain after the procedure. ${ }^{[12]}$ In another placebocontrolled trial, Dogan et al. showed that naproxen when combined with lidocaine was effective in relieving pain during endometrial biopsy. ${ }^{[13]}$ Drotaverine is effectively used in gynecological conditions like dysmenorrhea and nongynecological conditions like renal colic and cholelithiasis. ${ }^{[8]}$ In the studies by Sharma et al. and Singh et al., drotaverine when used during labor was shown to accelerate the labor and no adverse effects were seen. ${ }^{[9,10]}$

In literature there are studies where plain NSAIDs were used for pain relief before minor gynecological procedures and compared 
with placebo, paracervical block, intrauterine lignocaine insertion, local spray of lignocaine gel, but the results were not conclusive..$^{[12-14]}$ Various reasons have been cited for this, like cultural factors for pain tolerance, race, diameter of the hysteroscope, etc. There is a paucity of similar studies on Indian women. The present study confirms the superiority of combination of drotaverine and mefenamic acid over paracervical block and intravenous sedation in pain relief for office hysteroscopy and endometrial biopsy, which is especially significant for developing countries like India, where needles may be recycled putting the patient at risk of acquiring viral diseases. Moreover, the combination of mefenamic acid and drotaverine is an oral drug; is cheaper, costing Rs. 2; less invasive than paracervical block (costing approximately Rs. 10-15) and intravenous sedation (costing approximately Rs. 30-40); and has got no major adverse effects. To our knowledge, this is the first study to evaluate the efficacy of oral drotaverine plus mefenamic acid and compare it with that of paracervical bock and with that of intravenous sedation for pain relief during office hysteroscopy and endometrial biopsy.

Yang and Vollenhoven have reviewed pain control in outpatient hysteroscopy and failed to obtain substantial conclusive evidence for the routine use of local anesthesia in outpatient hysteroscopy. ${ }^{[14]}$ Recent studies have shown that outpatient hysteroscopy and targeted biopsies can be performed in one sitting, called see-and-treat philosophy, without the need of analgesia and anesthesia; especially, speculum and volsellum forceps are not used and vaginoscopic approach is used for hysteroscopy. ${ }^{[15]}$ Many centers in the world, especially in western countries, are running hysteroscopy clinics using see-and-treat philosophy, where in one sitting, diagnosis and management are performed. They often use 3-mm hysteroscope and vaginoscopic approach without the use of speculum and volsellum, which do not need analgesia and anesthesia. ${ }^{[15]}$ However, 3-mm hysteroscope was not available in our center; and $5-\mathrm{mm}$ rigid hysteroscope was used along with volsellum and speculum without vaginoscopic approach, necessitating the use of analgesia and anesthesia. In the present study, a rigid 5-mm hysteroscope with $30^{\circ}$ fore-oblique view (Karl-Storz, Germany) was used, which did not have grasping forceps to take targeted biopsies in minor operation theater. Hence targeted biopsies could not be done.

Outpatient hysteroscopy has been used successfully for diagnostic purposes and for see-and-treat philosophy, as is evident from many papers on the subject - by Bettocchi et al.., ${ }^{[15]}$ Spiezio et al.,. ${ }^{[16]}$ Papalampros et al.. ${ }^{[17]}$ and Cicinelli et al. ${ }^{[18,19]}$ Hysteroscopy is a very useful modality in the diagnosis of varying grades of adhesions in genital tuberculosis, as has been seen in our experience. ${ }^{[20]}$

In the present study, randomization was done in the 3 groups: group I receiving combination of oral drotaverine hydrochloride and mefenamic acid 1 hour before the procedure; group II receiving $10 \mathrm{~mL}$ of $1 \%$ lignocaine hydrochloride paracervically 5 minutes before the procedure; and group III receiving intravenous diazepam and pentazocine 10 minutes before the procedure. As 'paracervical lignocaine' and 'intravenous diazepam with pentazocine' are the two commonly used drug modalities, we did not randomize into 4 
areas, that is, drotaverine alone, mefenamic acid alone, combination of mefenamic acid and drotaverine and placebo, as we wanted to compare the efficacy of the combination of drotaverine (antispasmodic) and mefenamic acid (antiprostaglandin) with that of commonly used drugs.

This study has few limitations, like the small number of patients, not blinded completely, not placebo controlled; also, other secondary outcome measures like blood pressure, heart rate and time taken for the procedure have not been evaluated. Since racial and cultural factors also contribute to the pain tolerance levels, large multicentered placebo-controlled trials need to be done to prove the efficacy of oral drotaverine and mefenamic acid for gynecological office procedures.

To conclude, the present study showed that oral combination of drotaverine with mefenamic acid is more effective in relieving pain during hysteroscopy and endometrial biopsy as compared with paracervical bock and intravenous sedation.

\section{ACKNOWLEDGMENTS}

We thank Martin and Harris Private Ltd., India, for supplying Drotin-M tablets.

\section{REFERENCES}

1. Nagele F, O'Connor H, Davies A, Mohamed H, Magos A. 2500 Outpatient hysteroscopies. Obstet Gynecol 1996;88:87-92.

2. Schoenfeld A, Goldmann JA, Levy E. Pentazocine and diazepam for minor gynaecological operations. Br J Anaesth 1974;46:385-6.
3. Kajve PP, Sarate GS. Local infiltration block supplemented by diazepam and pentazocine combination for tubal ligation. J Indian Med Assoc 1984:84:143-5.

4. De Jong $\mathrm{P}$, Doel F, Falconer A. Outpatient diagnostic hysteroscopy. Br J Obstet Gynaecol 1990;97:299-303.

5. Lau WC, Lo WK, Tam WH, Yuen PM. Paracervical anaesthesia in outpatient hysteroscopy: A randomized double blind placebo controlled trial. Br J Obstet Gynaecol 1999;106:356-9.

6. Vercellini $P$, Colombo A, Mauro F, Oldani S, Bramante T, Crosignani PG. Paracervical anesthesia for out patient hysteroscopy. Fertil Steril 1994;62:1083-5.

7. Blasko G. Pharmocology: a mechanism of action and clinical significance of a convenient antispasmodic agent: Drotaverine. J Am Med Assoc India 1998;1:63-9.

8. Romics I, Molnar DL, Timberg G, Mrklic B, Jelakovic $B$, Koszegis $G$, et al. The effect of drotaverine hydrochloride in acute colicky pain caused by renal and ureteric stones. BJU Int 2003;92:92-6.

9. Sharma JB, Pundir P, Kumar A, Murthy NS. Drotaverine hydrochloride $V s$ Valethamate bromide in acceleration of labor. Int $\mathrm{J}$ Gynecol Obstet 2001;4:43-8.

10. Singh KC, Jain P, Goel N, Saxena A. Drotaverine hydrochloride for augmentation of labor. Int $\mathrm{J}$ Gynecol Obstet 2004;84:17-22.

11. Broadbent JA, Hill NC, Molnar BG, Rolfe KJ, Magos AL. Randomized placebo controlled trial to assess the role of intracervical lignocaine in outpatient hysteroscopy. Br J Obstet Gynecol 1992;99:777-80.

12. Nagele F, Lockwood G, Magos AL. Randomized placebo controlled trial of mefenemic acid for premedication at outpatient hysteroscopy: A pilot study. Br J Obstet Gynaecol 1997;104:842-4.

13. Dogan E, Celiloglu M, Sarihan E, Demir A. Anesthetic effect of intrauterine lidocaine plus naproxen sodium in endometrial biopsy. Obstet 
Gynecol 2004;103:347-51.

14. Yang J, Vollenhoven B. Pain control in outpatient hysteroscopy. Obstet Gynecol Surv 2002;57: 693-702.

15. Bettocchi S, Ceci O, Nappi L, Di Venere R, Masciopinto V, Pansini V, et al. Operative office hysteroscopy without anesthesia: analysis of 4863 cases performed with mechanical instruments. J Am Assoc Gynecol Laparosc 2004;11:59-61

16. Di Spiezio Sardo A, Taylor A, Tsirkas P, Mastrogamvrakis $G$, Sharma M, Magos A. Hysteroscopy: A technique for all? Analysis of 5,000 outpatient hysteroscopies. Fertil Steril 2008;89:438-43.

17. Papalampros $P$, Gambadauro P, Papadopoulos N, Polyzos D, Chapman L, Magos A. The miniresectoscope: A new instrument for office hysteroscopic surgery. Acta Obstet Gynecol Scand 2009;88:227-30.

18. Cicinelli E, Rossi AC, Marinaccio M, Matteo M, Saliani N, Tinelli R. Predictive factors for pain experienced at office fluid minihysteroscopy. J Minim Invasive Gynecol 2007;14:485-8.

19. Cicinelli E. Diagnostic minihysteroscopy with vaginoscopic approach: rationale and advantages. J Minim Invasive Gynecol 2005;12:396-400.

20. Sharma JB, Roy KK, Pushparaj M, Kumar S. Hysteroscopic findings in women with primary and secondary infertility due to genital tuberculosis. Int J Gynaecol Obstet 2009;104:49-52.

Source of Support: Martin and Harris Private Ltd., India, for supplying Drotin-M tablets, Conflict of Interest: None declared.

\section{Author Help: Reference checking facility}

The manuscript system (w ww.journalonw eb.com) allows the authors to check and verify the accuracy and style of references. The tool checks the references with PubM ed as per a predefined style. Authors are encouraged to use this facility, before submitting articles to the journal.

- $\quad$ The style as well as bibliographic elements should be $100 \%$ accurate, to help get the references verified from the system. Even a single spelling error or addition of issue number/month of publication will lead to an error when verifying the reference.

- $\quad$ Example of a correct style Sheahan P, O'leary G, Lee G, Fitzgibbon J . Cystic cervical metastases: Incidence and diagnosis using fine needle aspiration biopsy. Otolaryngol Head Neck Surg 2002;127:294-8.

- $\quad$ Only the references from journals indexed in PubM ed will be checked.

- $\quad$ Enter each reference in new line, without a serial number.

- Add up to a maximum of 15 references at a time.

- If the reference is correct for its bibliographic elements and punctuations, it will be shown as CORRECT and a link to the correct article in PubM ed will be given.

- If any of the bibliographic elements are missing, incorrect or extra (such as issue number), it will be shown as INCORRECT and link to possible articles in PubM ed will be given. 